\title{
Modification of polyethylene terephthalate track etched membranes by planar magnetron sputtered $\mathrm{Ti} / \mathrm{TiO}_{2}$ thin films
}

\author{
Arnoux Rossouw $^{\text {a,b, }{ }^{*}, \text { Olga Kristavchuk }}{ }^{\mathrm{a}}$, Andrzej Olejniczak ${ }^{\mathrm{a}, \mathrm{d}}$, Chris Bode-Aluko ${ }^{\mathrm{f}}$, \\ Boris Gorberg ${ }^{\mathrm{e}}$, Alexander Nechaev ${ }^{\mathrm{a}, \mathrm{c}}$, Leslie Petrik ${ }^{\mathrm{f}}$, Willem Perold ${ }^{\mathrm{b}}$, Pavel Apel ${ }^{\mathrm{a}, \mathrm{c}}$ \\ a Joint Institute for Nuclear Research, st. Joliot-Curie 6, Dubna, Moscow region, 141980 Russian Federation \\ ${ }^{\mathrm{b}}$ Faculty of Engineering, Stellenbosch University, 7602, Stellenbosch, South Africa \\ ${ }^{c}$ Dubna State University, st. Universitetskaya 19, Moscow region, 141980 Russian Federation \\ d Faculty of Chemistry, Nicolaus Copernicus University in Toruń, Poland \\ e Ivanovo State University of Chemistry and Technology, Sheremetevskii pr. 7, Ivanovo, 153000 Russian Federation \\ ${ }^{\mathrm{f}}$ Department of Chemistry, University of the Western Cape, 7535, South Africa
}

\section{A R T I C L E I N F O}

\section{Keywords:}

Titanium dioxide

Magnetron sputtering

Thin film

Polyethylene terephthalate

Track membrane

Surface modification

\begin{abstract}
A B S T R A C T
This study investigates the surface modification of polyethylene terephthalate track-etched membranes by planar magnetron sputtering of titanium and titanium dioxide thin films to improve its hydrophilicity and photocatalytic activity. After cold plasma treatment to enhanced adhesion, Ti thin films were deposited by planar magnetron sputtering and $\mathrm{TiO}_{2}$ thin films by reactive magnetron sputtering in an $\mathrm{Ar}-\mathrm{O}_{2}$ gas atmosphere. The morphology of the deposited thin films was characterised using atomic force microscopy and scanning electron microscopy. The pores retained a mostly circular shape. However, the modified track membrane's surface pore diameter reduced from $0.2 \mu \mathrm{m}$ to $0.15 \mu \mathrm{m}$ for $\mathrm{Ti}$ coated samples and $0.08 \mu \mathrm{m}$ for $\mathrm{Ti}^{-\mathrm{TiO}_{2}}$ coated samples. Structural studies using X-ray photoelectron spectroscopy, energy-dispersive X-ray spectroscopy and Raman spectroscopy of $\mathrm{Ti}$ and $\mathrm{TiO}_{2}$ thin films revealed the intricate composition of the sputtered thin films which was a result of the complexity of sputtering on top of the porous polymer support. Additional investigations in surface wettability and bandgap showed a significant change in the track membrane surface's hydrophilicity and photocatalytic properties after depositing $\mathrm{TiO}_{2}$ - $\mathrm{Ti}$, adding to the self-cleaning properties of the coated TM. The bandgap of the film was $3.1 \mathrm{eV}$ and of the indirect type. Both $\mathrm{Ti}$ and $\mathrm{TiO}_{2}$ - $\mathrm{Ti}$ sputtering over the TM surface significantly reduced the water contact angle from $72^{\circ}$ for untreated PET to $43^{\circ}$ and $45^{\circ}$ for $\mathrm{Ti}-\mathrm{TM}$ and $\mathrm{TiO} 2_{2}-\mathrm{Ti}^{-}$ TM, respectively. This study shows that planar magnetron sputtering is a viable approach to surface modification of a porous polymeric support, such as track-etched membranes. The sputtered coating enhanced membrane hydrophilicity, thereby reducing the chance of surface fouling by organic substances, which leads to improved self-cleaning properties.
\end{abstract}

\section{Introduction}

Track etched membranes (TM) are thin polymer films with an "engineered" pore structure. The pores are formed by irradiating the polymer film with swift-heavy-ions. The film, is then treated physiochemically in order to develop the latent tracks by removing the polymer material impacted by the trajectory of the swift-heavy-ions, thereby forming the pores [1,2]. Polyethylene terephthalate (PET) polymer is used for the majority of TMs in production. PET TMs in particular has several exceptional structural features that distinguish them from other traditional polymers and from native PET membranes, namely well-defined and modulated pore-geometry, pore-diameter and a controlled ratio of pores vs. unit surface area.

TMs are typically applied in medicine, for example in the purification of drugs and viral suspensions (vaccines); in obtaining blood plasma (plasmapheresis treatment); and in bacteriological quality control of food and water; for cleaning air and liquids, for example, in creating clean rooms; in drinking water purification systems; and in analytical control of substances [1,3-5].

Proliferation in the purview of track-etched membranes can be linked to both the increased demand for smart materials and the rising requirement for purity and finer filtration. However, high

\footnotetext{
* Corresponding author.

E-mail address: rossouw@jinr.ru (A. Rossouw).
} 
hydrophobicity is one of the primary disadvantages of most industrial membranes as it can lead to fouling of the membrane surfaces by organic matter. When membrane fouling occurs, a gel-like layer forms over the membrane surface, resulting in reduced efficiency and providing a possible breeding ground for bacteria. Consequently, not only can primary contamination from the feed enter the filtrate, but also secondary contamination from the by-products produced in the sludge [6].

The need for finer filtration is increasing in processes using microfiltration, ultrafiltration, nanofiltration, or reverse osmosis, primarily as a result of operational needs of the pharmaceutical and biopharmaceutical, microelectronics, life sciences, and analytical industry. Track etched membranes have been recognized as one of the only available technologies to achieve, and verify, the required level of filtration. Nevertheless, these material properties are not always obtainable through conventional processing technologies. Often, surface modifications are required without altering the bulk of the TM structure [7-10]. However, since the range of polymers viable for membrane manufacturing are limited, off the shelf commercial products are frequently inconsistent with the various industrial or technology needs. Further research into membrane surface modification is necessary to broaden the scope of their application.

The two main routes for customising TM properties are to either synthesise a new polymer composition or by physicochemical modification of the TM itself. For example, by altering the pore shape from symmetrical to asymmetrical, one can improve the filtration properties of the TM by reducing their hydrodynamic resistance without sacrificing durability and permeability [11-13]. An efficient method for surface modification of polymeric TMs is through the deposition of thin films of various materials (metal/ceramic) upon its surface. This could be achieved through either Chemical vapour Deposition or Physical vapour Deposition. However, for the purposes of this study we have chosen the latter, specifically Planar Magnetron Sputter Deposition, as it is more suited for upscaling to industrial-scale roll-to-roll deposition on polymeric TMs [7-10].

Magnetron sputter deposition can be subdivided into different categories based on power supply (direct current, pulsed direct current, alternating current, radio frequency), target type (planar, cylindrical, rotatory) and magnet configuration (balanced, unbalanced, rotatory). In this study, a magnetron that makes use of planar targets, a direct current (DC) power supply, and unbalanced magnets was chosen [7]. Currently, magnetron sputtering is not being used on an industrial scale for the surface modification of PET-TM, because of the specific requirements and peculiarities related to TMs. There are problems, both scientific and engineering related, to be solved before implementing this method in the TM industry. Polymer materials generally have a low surface energy and, consequently, low adhesion characteristics. For better adhesion of coatings to the polymer, pre-activation of the surface is recommended [14-17].

Degassing is a major problem when sputtering on a TM, especially at a large scale. The treatment of the TM in a low-pressure plasma is accompanied by the release of absorbed water from the polymer. This results in the formation of various impurities and gaseous by-products formed through the interaction between the plasma, the vacuum, and the polymer. This imposes special requirements on the vacuum equipment and process regime [7]. Temperature regulation is imperative due to the potential difference in the expansion coefficient between TM and metals/ceramics during deposition. Should the TM heat-up and expand during sputtering, it could lead to the delayed formation of cracks in the coatings [18-20].

Magnetron sputtering does, however, offer several advantages: Versatility, due to the possibility of obtaining films of metals, alloys, semiconductors, and dielectrics; Adaptability, due to the possibility to combine multiple processes in the same chamber, including substrate surface activation, without breaking vacuum; Control, due to the possibility to alter the coating structure and properties by varying the discharge power, chamber pressure and composition/flow of the carrier and reactive gas medium [7].

Titanium (Ti) has been chosen as the target coating as it is possible to deposit both $\mathrm{Ti}$ and Titanium dioxide $\left(\mathrm{TiO}_{2}\right)$ from the same target without breaking vacuum. $\mathrm{TiO}_{2}$ is one of the most widely used photocatalysts due to its extensive range of applications such as water and air purification, its optical, electrical, and chemical properties as well as the relative ease with which it can be implemented in mass production [8, 10,14,21-26]. Some advantages of metallised polymeric TMs over its native counterpart includes improved chemical resistance, increased mechanical strength, a higher thermal stability, and the formation of asymmetrical pores because of the single sided metallisation. All these changes due to the surface metallisation by $\mathrm{Ti}$ and $\mathrm{TiO}_{2}$, leads to an increased productivity of the resulting TM [27-29]. Particular interest is focused on enhancing the properties of TM to induce photocatalytic properties for purposes of self-cleaning and antifouling [30-32]. Details on the research and development in deposition of metal-ceramic coatings on the surface of polymeric TMs are few and far between.

In view of this lack of information relating to magnetron sputtering surface modification of TMs, which possesses a porous structure, it is necessary to gain insight into the inner workings of plasma reactions with TM. Modernising membrane filtration technology utilising TMs is an attractive solution to areas such as drinking water treatment, extractive industrial water treatment, industrial gas separation, domestic air filtration, and biochemical sensing. TMs could be used in preference to conventional separation methods. Therefore, the present work aims to partially fill this knowledge gap by determining how the properties of the resulting thin films being deposited on TMs depend not only on the deposition conditions but on the specific features and the chemical nature of the porous-polymer TM. As we show, the proposed magnetron sputtered layers would significantly improve the hydrophilicity of the surface. The bandgap in the near-UV region, coupled with the modified surface, is expected to reduce fouling, and enhance selfcleaning via photocatalysis of the organic contaminants retained on the membrane. Thus, this study aims to pave the way to industrialising the TM surface modification process for future filtration applications.

\section{Experimental}

\subsection{Ti and $\mathrm{TiO}_{2}$ film deposition}

The exterior of $23 \mu \mathrm{m}$ thick PET TMs, with a pore-diameter of $0.2 \mu \mathrm{m}$ and a pore-density of $5 \times 10^{8} \mathrm{~cm}^{-2}$, was modified through DC magnetron sputtering of $\mathrm{Ti}$ and $\mathrm{TiO}_{2}$ directly on top of the surface. All membranes were manufactured in the Flerov Laboratory of Nuclear Reactions (FLNR) at the Joint Institute for Nuclear Research from polyethylene terephthalate (PET) film. The entire TM production procedure has previously been described by Flerov et al. [33] and Apel and Dmitriev [34].

To clean and degrease the TM's surface before sputter deposition, the polymer support was pre-treated for $1 \mathrm{~min}$ at $5 \times 10^{-3} \mathrm{~Pa}$ by cold plasma. This also leads to the temporary formation of oxygen-containing functional groups on the TM surface that help improve adhesion during sputtering [35,36]. Using a MIR-2 magnetron sputtering system, in DC mode, metallic Ti films were sputtered directly on top of the pre-treated TM surface at a deposited rate of $4-5 \AA / \mathrm{s}$. A horizontally mounted sputter target (cathode) made of $99.7 \%$ pure titanium in a chamber filled with a $99,99 \%$ pure argon carrier gas at a pressure of $2.67 \times 10^{-1}$ $\mathrm{Pa}$, and a current of $3 \mathrm{~A}$ was used to deposit the Ti coatings at a target-to-substrate distance of $240 \mathrm{~mm}$.

Sputtering of $\mathrm{TiO}_{2}$ on top of the Ti coated TM was carried out inside the MIR-2 magnetron sputtering system without breaking vacuum at a deposited rate of 2-3 $\AA /$ s. The only change was the addition of a reactive gas to the argon atmosphere. For $\mathrm{TiO}_{2}$ deposition, a mixture of argonoxygen at a pressure of $2.67 \times 10^{-1} \mathrm{~Pa}$ and $0.67 \times 10^{-1} \mathrm{~Pa}$ was used respectively [37]. Additional $\mathrm{TiO}_{2}$ - $\mathrm{TM}$ samples without the Ti layer were made for XPS and band-gap analysis as a control specimen.

Please note that in this article: 
- TM refers to all uncoated track etched membrane samples;

- Ti-TM will refer to track etched membranes coated in titanium;

- $\mathrm{TiO}_{2}$-TM will be considered the control and refers to all track etched membrane samples coated in only titanium dioxide;

- $\mathrm{TiO}_{2}$-Ti-TM will refer to all track etched membranes first coated by titanium, and then coated thereafter by titanium dioxide;

- All deposition parameters have been optimised for this experiment; however, this process will not be discussed in detail as it is not the focus of this paper.

\subsection{Ti and $\mathrm{TiO}_{2}$ film characterisation}

The surface morphology was studied by atomic force microscopy (AFM) and scanning electron microscopy (SEM). AFM images were recorded using a Ntegra (NT-MDT, Russia) microscope operating in tapping mode with standard NSG10 cantilever tips. The deposition rate was determined by initially sputtering $\mathrm{Ti}$ and $\mathrm{TiO}_{2}$ on glass and thereafter measuring the film thickness by atomic force microscopy (AFM). Scanning electron microscopy (SEM) was performed using a SU-8020 high-resolution field-emission SEM (Hitachi, Japan) at an operating voltage of 3-5 kV. Element distributions were primarily investigated for $\mathrm{C}, \mathrm{N}_{2}, \mathrm{O}_{2}$ and $\mathrm{Ti}$ by energy dispersive spectroscopy (EDS) at a working distance of $14.10 \mathrm{~mm}$, elevation angle of $29.22^{\circ}$, collection time of $60 \mathrm{~s}$ and an accelerating voltage of $3-10 \mathrm{kV}$, performed on a SEM with Oxford Instruments Aztec Energy EDS Analysis System.

X-ray photoelectron spectroscopy (XPS) measurements were carried out using a Thermo Fisher K-Alpha X-ray spectrometer equipped with a monochromatized Al K $\alpha$ X-ray source (1486.68 eV) and an ion gun for depth profiling. Survey spectra were obtained with a pass energy of 100 $\mathrm{eV}(0.5 \mathrm{eV}$ step) whereas the high-resolution region scans were taken with $0.05 \mathrm{eV}$ step and a pass energy of $20 \mathrm{eV}$. The binding energy (BE) scale of the spectrometer was calibrated using sputter-cleaned samples of pure copper (Cu 2p3/2, 932.62 eV), silver (Ag 3d5/2, 368.21 eV), and gold ( $\mathrm{Au} 4 \mathrm{f7} / 2,83.96 \mathrm{eV}$ ). Since the $\mathrm{TiO}_{2}$-Ti-TM and Ti-TM film coating layers were conductive, no charge neutralisation was applied during spectral acquisition. For non-conductive $\mathrm{TiO}_{2}$-TM specimen, a dual beam charge neutralizer (flood gun) was used to minimize charging of the surface. In this case, to eliminate shifts in the electron BE scale, the spectra were referenced to the deconvoluted $\mathrm{Ti} 2 \mathrm{p} 3 / 2$ peak of $\mathrm{TiO}_{2}$ at $458.60 \mathrm{eV}$. A deconvolution procedure was carried out with a standard Shirley background and a mixed Gaussian-Lorentzian GL( $x)$ line shape or Gaussian-Lorentzian Convolution $\operatorname{LA}(\alpha, \beta, m)$. Our notation is consistent with that of CasaXPS software, that is, for GL line, $x$ is the percentage of the Lorentzian share in the Gaussian/Lorentzian product formula; for LA peak $\alpha$ and $\beta$ specify the spread of the tail of the Lorentz curve and $m$ is the width of Gaussian used to convolute the Lorentz curve. Note that, for $\alpha \neq \beta$, the spread of the tail on one side of LA line is different than on the other side, producing an asymmetric line shape. In order to investigate the bulk composition of the films, the depth profiling, consisting of repeating 10 s etching cycles with $2 \mathrm{keV} \mathrm{Ar}+$ ions followed by a subsequent XPS analysis.

Raman spectroscopy was used to investigate the structure of the deposited $\mathrm{Ti}$ and $\mathrm{TiO}_{2}$ films. Raman spectra were collected using a Raman spectrometer (EnSpectr R532, Chernogolovka, Russia) with a green $532 \mathrm{~nm}$ laser as monochromatic light excitation source.

Ultraviolet-visible spectroscopy was used to collect the spectra of the $\mathrm{TiO}_{2}$-TMs using an Evolution 600 (Thermo Scientific UV-VIS, USA) in the wavelength range $190-900 \mathrm{~nm}$, thereafter the data was processed to determine the band gap energy.

Contact-angle measurements were carried out at room temperature to analyse the hydrophobicity/hydrophilicity effect of the metallisation on the TMs using a Krüss DSA100 Drop shape analysis System (Krüss $\mathrm{GmbH}$, Germany). The approach involved meticulously placing a $3 \mathrm{~mL}$ droplet of deionised water (18.2 MOm•cm, Milli-Q Advantage A10, Millipore, USA) on the sample surface. Thereafter, using the DSA4 (Krüss GmbH, Germany) software, the procurement of an image of the droplet and the ensuing computation of both contact-angles (left and right) was completed within $3 \mathrm{~s}$.

\section{Results and discussions}

For a qualitative understanding of the thin sputtered layers of metallic-Ti and dielectric- $\mathrm{TiO}_{2}$ on top of their track membrane supports, as well as the physicochemical properties of the deposited thin films, it is necessary to investigate the relationship between morphology, composition and the structure of the modified membranes. Track membranes are a good model of a porous supporting structure, especially for investigating thin films deposited by magnetron sputtering. Investigating changes of pore size and geometry, together with the layer-bylayer composition of the thin-film material, can be used to give insights into the production and advantages of these thin films.

\subsection{Morphological study by atomic force microscopy (AFM) and scanning electron microscopy (SEM)}

AFM data can be useful in tailoring the product coating thickness, roughness, and grain structure by fine-tuning the sputtering parameters (e.g., power, pressure, gas composition). The deposition rate was initially estimated by depositing $\mathrm{Ti}$ and $\mathrm{TiO}_{2}$ films on top of silicon wafers and measuring the resulting step-edge. The thickness of the sputtered metallic Ti was between 40 and $50 \mathrm{~nm}$, deposited at a rate of 4-5 $\AA / s$, and the thickness of the ceramic $\mathrm{TiO}_{2}$ was approximately 90-100 nm, deposited at a rate of $2-3 \AA$ s.

In the determination of surface morphology, small areas between the pores were chosen for AFM measurements to avoid pore influence. The root-mean-square deviation of the surface profile (Rq) is equal to $9.6 \pm$ $0.4 \mathrm{~nm}$ for the initial membrane. The argon plasma treatment causes a smoothing of the surface's structural heterogeneities, leading to the $\mathrm{Rq}$ value decreasing to $4.6 \pm 0.4 \mathrm{~nm}$. Sputter deposition of $\mathrm{Ti}$ and $\mathrm{TiO}_{2}$ increased the overall surface roughness between the pores. $\mathrm{Rq}=5.3 \pm$ $0.4 \mathrm{~nm}$ for Ti-TM and $\mathrm{Rq}=6.4 \pm 0.4 \mathrm{~nm}$ for $\mathrm{TiO}_{2}$-Ti-TM.

In Fig. 1a, the initial TM surface shows the presence of spherulites with quite uniform sizes and -spatial distribution. Such surface morphology developed due to the PET film's chemical etching after ion irradiation and is consistent with [38]. In the $\mathrm{TiO}_{2}$-Ti-TM sample, Fig. 1c, the grain size distribution seems to be more uniform than in the case of the Ti-TM sample, Fig. 1b. Nevertheless, for both the Ti-TM and $\mathrm{TiO}_{2}$-Ti-TM samples, larger grains seem to be composed of smaller particles. It might be because coated TMs retain some resemblance to the spherulite structure of the supporting TM.

After Ti sputtering, the post-deposition surface topography as seen by SEM remained similar to that of the track membrane, see Fig. $2 b$. The pores retained a mostly circular shape with a reduction in diameter from $0.2 \mu \mathrm{m}$ to $\approx 0.15 \mu \mathrm{m}$. However, TMs coated with both $\mathrm{Ti}$ and $\mathrm{TiO}_{2}$ differed notably from those only coated in Ti. The SEM investigation revealed that after sputtering the consecutive $\mathrm{TiO}_{2}$ layer, a partial occlusion of the pores occurred, see Fig. 2c. This resulted in a distortion in both of the shape of the pore's edge and its effective diameter. The derived pore diameter significantly reduced from the native TM, from $0.2 \mu \mathrm{m}$ to $\approx 0.08 \mu \mathrm{m}$. Keep in mind that in Fig. $2 \mathrm{~b}$, based on the estimated deposition rate, the total film thickness is $\approx 40 \mathrm{~nm}( \pm 10 \%)$ compared to $\approx 140 \mathrm{~nm}( \pm 10 \%)$ in that of Fig. 2c. For TMs the bubble point method is the industry standard for pore size determination, but unlike SEM, it does not have the visual aspect allowing us to see artefacts such as the "narrow" pore visible at the top left-hand corner in Fig. 2c. However, upon closer investigation this narrow pore is not actually a single pore, but a double pore formed by 2 swift heavy ions intersecting the TM during ion irradiation, only appearing as a single narrow pore after being sputter coated by $\mathrm{Ti}$ and $\mathrm{TiO}_{2}$.

AFM and SEM analysis of the modified TM surface morphology revealed a $15 \%$ higher surface RMS roughness for the Ti- and a $40 \%$ higher surface RMS roughness for the $\mathrm{TiO}_{2}$-Ti coated membranes 

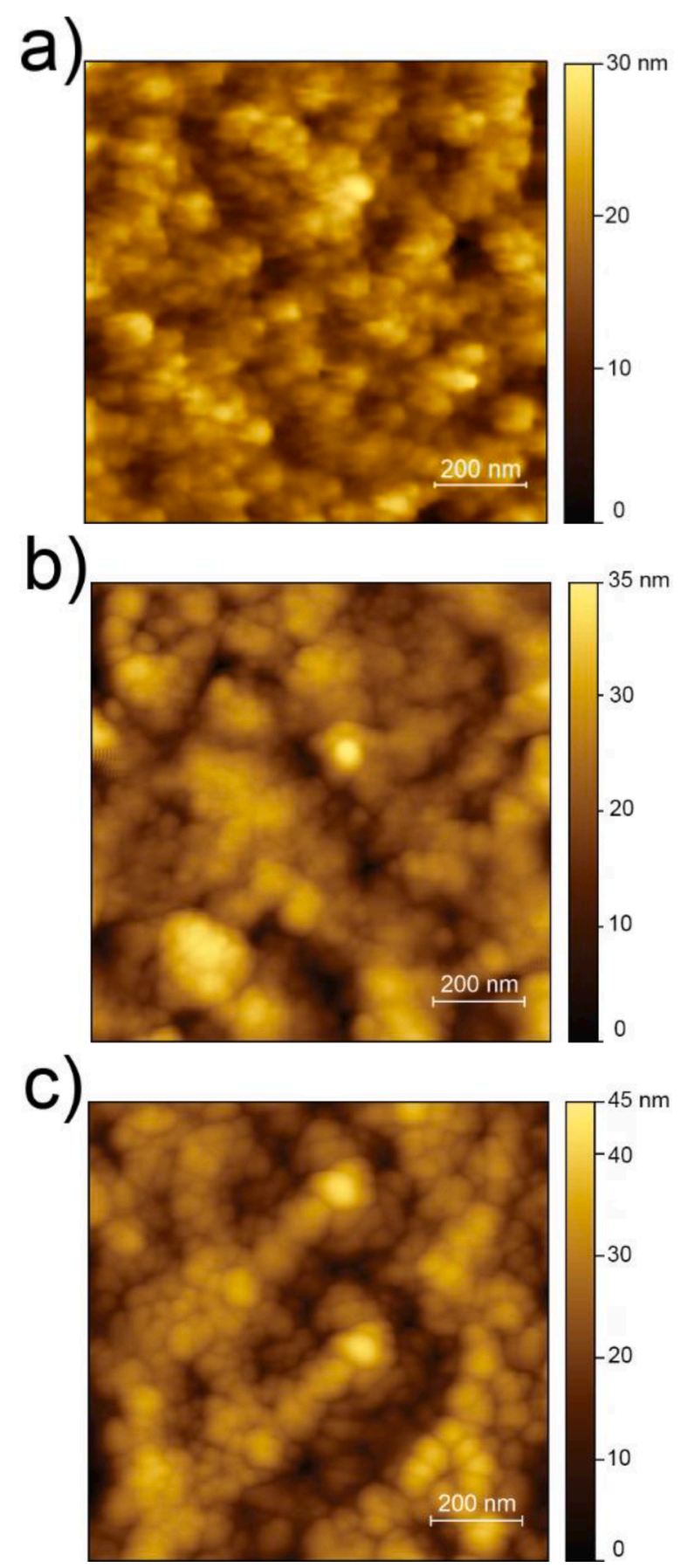

Fig. 1. AFM height images of: (a) TM, (b) Ti-TM, and (c) $\mathrm{TiO}_{2}$-Ti-TM sample. The image size is $1 \times 1 \mu \mathrm{m}^{2}$. Note that areas without the pores were chose for the AFM investigation.

compared to that of the uncoated TM. The deposited thin films appear to be somewhat granular and made up of particles $\approx 15-50 \mathrm{~nm}$ in diameter. This is thought to be advantageous for applications where an enlarged surface area benefits processes such as adsorption and heterogenous catalysis. Additionally, it is believed that further research and development into the sputtering methodology on top of TM supports would result in a less noticeable alteration to the pore shape.

3.2. Compositional study by X-ray photoelectron spectroscopy (XPS), energy dispersive $X$-ray spectroscopy (EDS) and raman spectroscopy

XPS is a powerful surface analysis tool for materials research and
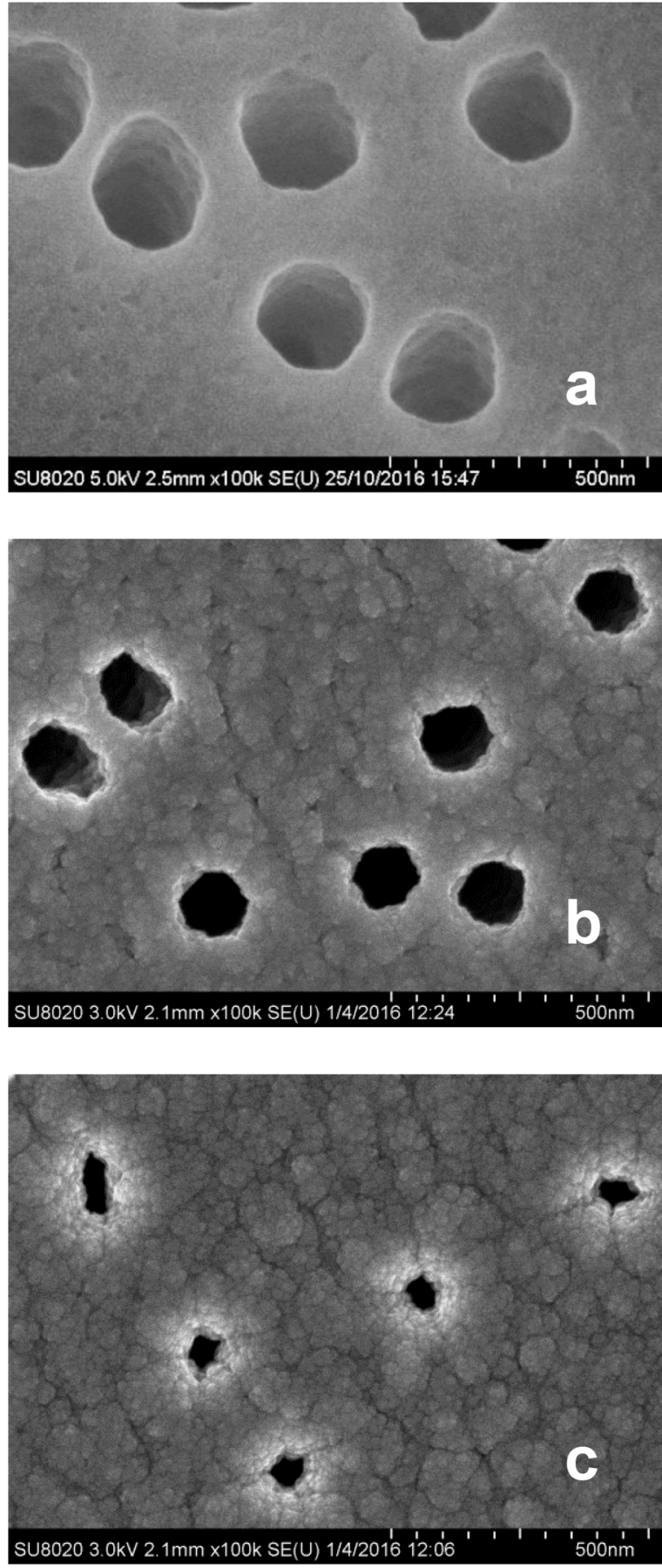

Fig. 2. SEM micrographs of a) $\mathrm{TM}, \mathrm{b}) \mathrm{Ti}-\mathrm{TM}, \mathrm{c}) \mathrm{TiO}_{2}-\mathrm{Ti}-\mathrm{TM}$.

problem solving used to elucidate the surface chemistry responsible for both the wettability and catalytic characteristics of $\mathrm{TiO}_{2}$ thin films [25]. This technique was used in this study to investigate both the bulk and surface chemical composition of the $\mathrm{Ti}$ and $\mathrm{TiO}_{2}$ films in order to identify the chemical state of the Ti atoms in particular.

The Ti2p reference spectrum for crystalline $\mathrm{TiO}_{2}$ has a broad GL(30) line and symmetric LA(1.5, $1.5,70)$ peak for the $j=3 / 2$ and the $j=1 / 2$ component respectively. Spin-orbit splitting of $5.72 \mathrm{eV}$ was assumed and the area ratio of $\mathrm{Ti} 2 \mathrm{p} 1 / 2$ to $\mathrm{Ti} 2 \mathrm{p} 3 / 2$ component was constrained to $1: 2$, in accordance with the literature [39]. This model fitted the Ti $2 p$ core level spectrum of $\mathrm{TiO}_{2}$-TM fairly well, see Fig. 3a, suggesting the appropriate choice of sputtering conditions.

A more complex picture was obtained for Ti $2 p$ surface spectrum of 

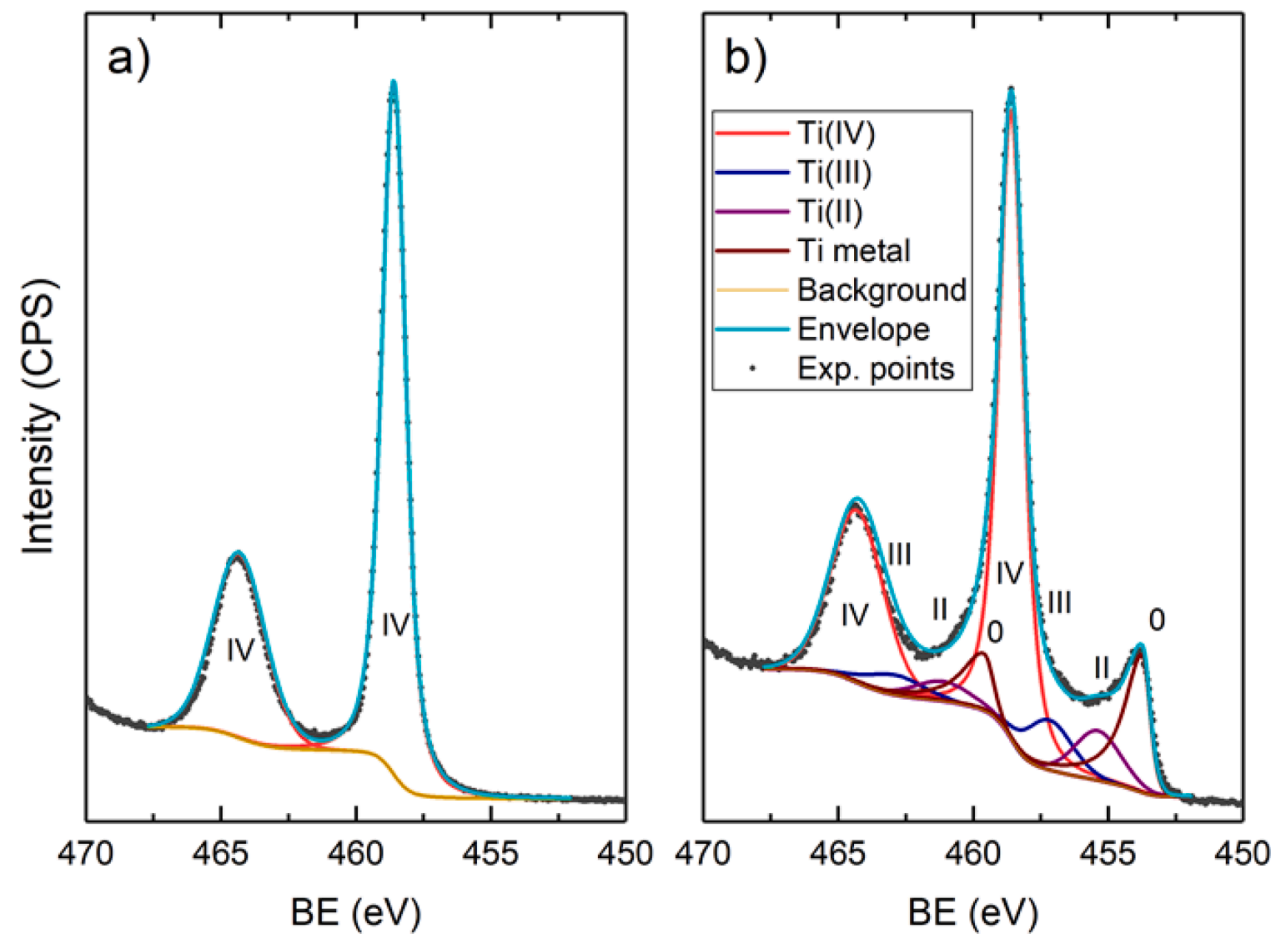

Fig. 3. Ti $2 \mathrm{p}$ core level spectra recorded on the surface of (a) $\mathrm{TiO}_{2}-\mathrm{Ti}-\mathrm{TM}$ and (b) $\mathrm{Ti}-\mathrm{TM}$ specimens.

the Ti-TM sample, see Fig. 3b. In this case, as expected an asymmetric component due to metallic Ti was visible at low BE range. However, the main constituent of the sputtered layer was still $\mathrm{TiO}_{2}$. Following literature recommendations the deconvolution was carried out by setting spin-orbit splitting to $5.7 \mathrm{eV}$ for oxides and BE shifts of - $1.4 \mathrm{eV}$ for Ti(III) oxide and $-3.2 \mathrm{eV}$ for $\mathrm{Ti}(\mathrm{II})$ oxide, related to respective $\mathrm{TiO}_{2}$ components [39]. For metallic components the asymmetry was accounted for by LA(1, 1.5, 7) line and spin-orbit splitting was set as $6.03 \mathrm{eV}$. The BE values of metallic components were slightly lower $(\approx$ $0.1 \mathrm{eV}$ ) than typical literature values. The atomic ratio of $\mathrm{Ti}$ bound in $\mathrm{TiO}_{2}$ to $\mathrm{Ti}_{2} \mathrm{O}_{3}$ to $\mathrm{TiO}$ to $\mathrm{Ti}(0)$ was $8: 1: 1: 2[66.6 \%, 8.4 \%, 8.4 \%$, and $16.6 \%$. Since the sputtered layer contains some amounts of TiC and TiN
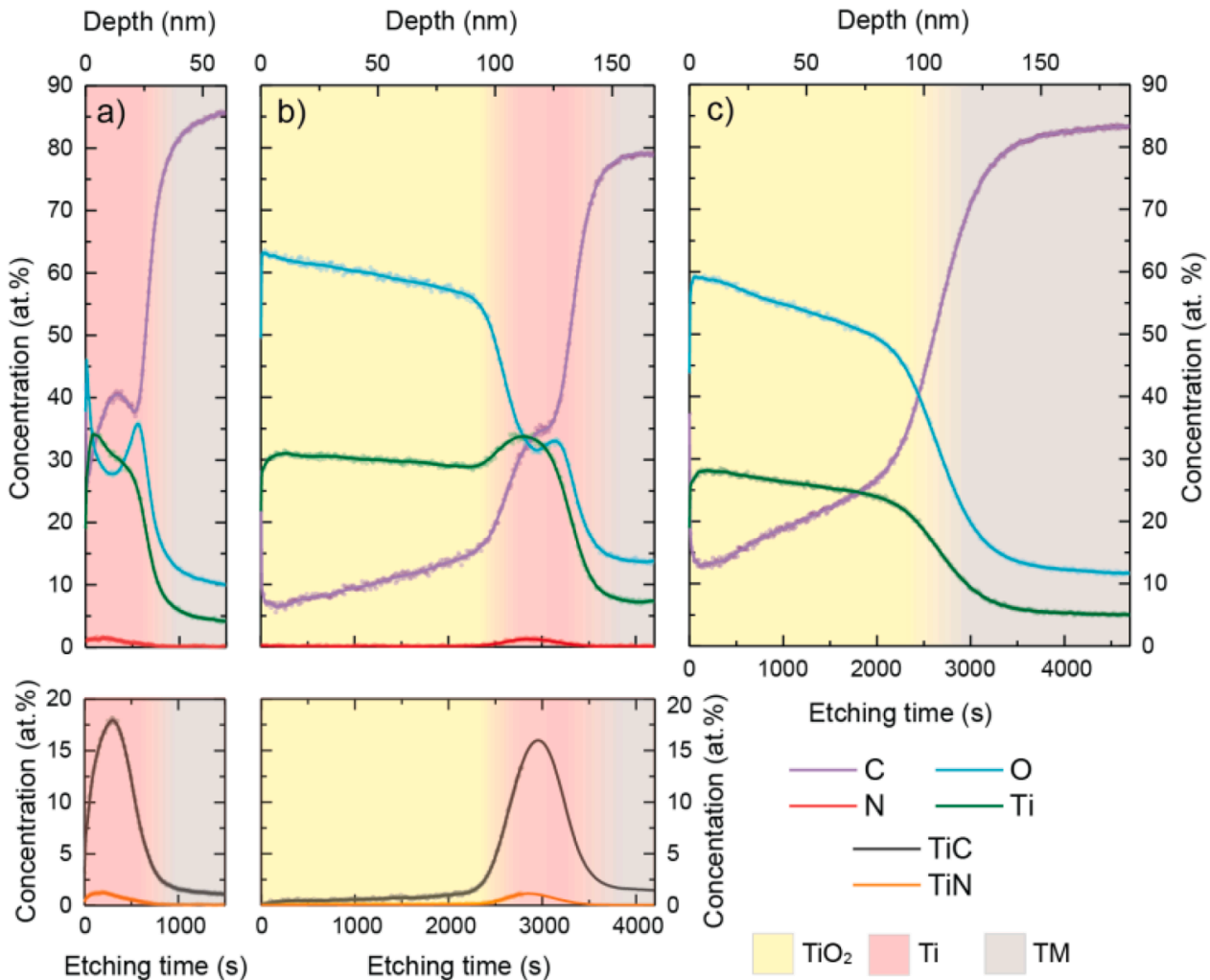

Etching time (s)

Etching time (s)

$\mathrm{TiO}_{2}$

TM

Fig. 4. XPS depth profiles for (a) $\mathrm{Ti}-\mathrm{TM}$, (b) $\mathrm{TiO}_{2}-\mathrm{Ti}-\mathrm{TM}$, and (c) $\mathrm{TiO}_{2}-\mathrm{TM}$ specimens. 
(see discussion below), the content of $\mathrm{Ti}$ bound in intermediate oxides, especially in TiO, is overestimated due to overlapping - Ti $2 \mathrm{p} 3 / 2$ lines of both TiN and TiC that are closely positioned at ca. $455 \pm 0.5 \mathrm{eV}[40,41]$.

To gain insight into the bulk composition of the thin films, depth profiling with monoatomic Ar ions was conducted. As known, under such etching conditions titanium oxides are gradually reduced to intermediate oxides or even $\mathrm{Ti}(0)$ [42], thus limiting the relevant information. A similar issue arises due to ion irradiation-induced deoxygenation of the polymer substrate $[43,44]$, making the elucidation of the actual composition virtually impossible. Thus, our considerations below are based primary on global changes in the elemental composition and analysis of stable species. The respective depth profiles obtained at $2 \mathrm{keV} \mathrm{Ar}+$ ion etching are shown in Fig. 4a-c. For each film, the initial concentration of $C$ atoms was high (30-40 at.\%), suggesting that the film surfaces are contaminated with a thin overlayer of adventitious carbon.

This contamination was readily removed after a few etching cycles. After that, for the Ti-TM specimen, see Fig. 4a, the content of Ti atoms decreased slowly until reaching the track membrane support. At this point a more dramatic reduction in the Ti content started. The initial decrease in the oxygen content is more significant and related to the socalled ion beam preferential sputtering [45-48]. This effect is reflected in the evolution of high-resolution Ti2p spectra, the share of low-oxidation state oxides and $\mathrm{Ti}(0)$ increases at the expense of $\mathrm{TiO}_{2}$. At the Ti-TM interface the level of $\mathrm{O}$ increases, forming on its concentration profile a peak centred at etching time of $\approx 550 \mathrm{~s}$. This is related to the oxygen content in the PET substrate, that is initially higher, but quickly decreases upon ion bombardment.

For $\mathrm{TiO}_{2}$-Ti-TM, see Fig. 4b, a clear transition between the first $\mathrm{TiO}_{2}$ and second $\mathrm{Ti}$ sputtered regions is visible. Throughout the $\mathrm{TiO}_{2}$ layer the content of $\mathrm{Ti}$ atoms stays relatively constant $(\approx 30$ at.\%). The initial oxygen content is approx. two times higher than that of titanium. With increasing etching time the $\mathrm{O}$ share slowly decreases. However, until a Ti sputtered layer is reached (at approx. 2400s), it is still higher than in the case of the Ti-TM film. This confirms that the major constituent of this layer is $\mathrm{TiO}_{2}$. Along the $\mathrm{Ti}$ interlayer and for the interface with $\mathrm{TM}$ the changes in atomic concentrations are similar to those of Ti-TM. For $\mathrm{TiO}_{2}$-Ti-TM, a composition of Ti interlayer cannot be obtained directly. However, based on the fact that the content of Ti here is higher and similar to that in Ti-TM film ( $\approx 35$ at.\%), a similar mixture of oxides and Ti(0) can be assumed.

For better clarity, a control sample was prepared and investigated. The $\mathrm{TiO}_{2}$-TM film, see Fig. $4 \mathrm{c}$, atomic concentration profile is similar to that of the $\mathrm{TiO}_{2}$ layer in the $\mathrm{TiO}_{2}$-Ti-TM film. The most notable difference is the interface with the TM support. The absence of the region with increased oxygen content may suggest that TM near the surface region has undergone deoxygenation due to the more severe conditions of magnetron sputtering. It should be pointed out that for each film investigated, after etching the entire deposited film, some amount of $\mathrm{Ti}$ $(\approx 4-7.5$ at.\%) was still present. For this specimen we performed additional etching cycles that show that, after reaching the interface, this $\mathrm{Ti}$ amount does not change significantly for a relatively long etching process $(\approx 1000$ s). This behaviour suggests the presence of Ti inside the pores of the TM which is also evident in SEM images.

Based on the high-resolution region spectra, the concentration profiles of $\mathrm{TiC}(\mathrm{C} 1 \mathrm{~s}, \mathrm{BE}$ of $\approx 282 \mathrm{eV}$ ) and TiN (N1s, BE of $397 \mathrm{eV}$ ) were calculated for Ti-TM and $\mathrm{TiO}_{2}$-Ti-TM, see bottom of Fig. 4a-b. The shoulder peak at higher $\mathrm{BE}(\approx 399 \mathrm{eV})$ on $\mathrm{N} 1 \mathrm{~s}$ spectra was attributed to titanium oxynitride (TiNO) [41]. Since the ratio of TiNO to TiN was rather constant, to obtain more stable fitting results, a single asymmetric LA(1.1, 2.44, 69) line, accounting for both species, was used. A similar approach was applied to deal with a shoulder peak (BE of $282.7 \mathrm{eV}$ ) on the TiC signal on C1s spectra. In this case the shoulder is due to the interface or disorder effects [49] and was accounted for by an asymmetric $\mathrm{LA}(1.0,1.2,69)$ line of $\mathrm{TiC}$ component. For $\mathrm{TiO}_{2}$ - TM the concentrations of TiN and TiC were below detection limits. Similarly, the absence of TiN and only low content of $\mathrm{TiC}$ ( $<2$ at.\%) was noticed for the
$\mathrm{TiO}_{2}$ layer in $\mathrm{TiO}_{2}$-Ti-TM. Here, the level of $\mathrm{TiC}$ is clearly related to the presence of carbon contamination in the layer. The ratio of $\mathrm{C}$ in $\mathrm{TiC}$ to total $\mathrm{C}$ content is constant along the whole layer. For both Ti-TM, and $\mathrm{TiO}_{2}$ - Ti-TM the maximum levels of $\mathrm{TiC}$ and $\mathrm{TiN}$ are reached at the $\mathrm{Ti}$ layer close to the interface of the sputtered Ti layer and TM.

These findings, along with the presence of $C$ contamination in the deposited film, suggest that during the deposition process, the near surface layer of the TM undergoes partial chemical transformation. Similarly, as for other polymers, preferential deoxygenation of the film may occur. The atoms and clusters released from the TM support surface seemed to be highly reactive toward $\mathrm{Ti}$, leading to the formation of $\mathrm{TiC}$ and mixed titanium oxides. The increase carbon footprint throughout the layer is most likely as a result of self-sputtering and backscattering from the support.

Energy-dispersive microanalysis (Table 1) confirms the presence of the following elements: C, N, O, and Ti. Since the analysis was carried out at an electron acceleration voltage of $10 \mathrm{kV}$, the penetration depth of electrons with that high energy is in the range of up to $1000 \mathrm{~nm}$. Thus, a significant portion of the EDS signal comes from the polymer support, explaining the low content of $\mathrm{Ti}$ in both samples (Table 1 ). The content of $\mathrm{Ti}$ increases in the following order: $\mathrm{TM}<\mathrm{Ti}-\mathrm{TM}<\mathrm{TiO}_{2}$-Ti-TM and is clearly related to the thickness of magnetron sputtered layers. The concentrations of light elements should be considered semiquantitatively. The respective signals lie close to one another (C K $\alpha$ $277 \mathrm{eV}, \mathrm{N} \mathrm{K} \alpha 392 \mathrm{eV}$, O K $\alpha 25 \mathrm{eV}$ ), and in addition, the $\mathrm{O} \mathrm{K} \alpha$ signal is partially overlapped with the Ti L $\alpha$ line $(452 \mathrm{eV})$.

EDS confirmed the presence of $N$, nevertheless, it is difficult to give an exact estimate, especially when trying to differentiate between carbon and nitrogen, since their peaks are so close to one another. This is further complicated by the fact that the deposited $\mathrm{Ti}$ and $\mathrm{TiO}_{2}$ films are so thin. However, these results are consistent with the XPS depth profile and help to support the theory that, despite no obvious visual artifacts, there is some TM surface decomposition taking place during Ti sputtering. Thereby resulting in the unanticipated carbon contamination and subsequently, a TiC interfacial layer formed between the TM support and Ti coating.

Raman spectroscopy is a powerful non-invasive and non-destructive chemical analysis technique that allows for the investigation of modified vibrational structures of $\mathrm{TiO}_{2}$ (anatase, rutile and brookite), even in very small quantities, such as those found in thin films. Raman spectra of materials are like their fingerprint characteristics, the intensity, positions, and widths of the Raman bands of the measured materials are related to their vibrational and structural properties [50]. The Raman spectra was measured in the $200-2000 \mathrm{~cm}^{-1}$ range for TM, Ti-TM, $\mathrm{TiO}_{2}$-Ti-TM, see Fig. 5.

Raman active modes are located at around $260 \mathrm{~cm}^{-1}, 420 \mathrm{~cm}^{-1}$ and $610 \mathrm{~cm}^{-1}$. The peaks at $1564 \mathrm{~cm}^{-1}$ (G-band) and $1328 \mathrm{~cm}^{-1}$ (D-band) along with a broad symmetric 2D peak at approx. $2750 \mathrm{~cm}^{-1}$ (not shown) indicate the presence of turbostratic carbon. The spectral envelope suggests that the carbon phase has a highly disordered, but not yet fully amorphous, structure. The presence of turbostratic carbon is in accordance with our assumptions (based on XPS and EDS) that during the magnetron deposition the near-surface of the polymer film undergoes decomposition and a significant fraction of self-sputtered and backscattered carbon clusters from the substrate is trapped in the deposited films. In Fig. 5, the Raman active modes located at 262/269

Table 1

Elemental composition (from EDS data) of $\mathrm{Ti}$ and $\mathrm{TiO}_{2}$-Ti films deposited by magnetron sputtering on TM supports.

\begin{tabular}{lllll}
\hline \multirow{2}{*}{ Sample } & \multicolumn{2}{l}{ Concentration, at.\% } & C & N \\
& $\mathrm{Ti}$ & $\mathrm{O}$ & 75 & - \\
\hline $\mathrm{TM}$ & - & 23 & 65 & 4 \\
$\mathrm{Ti}-\mathrm{TM}$ & 8 & 23 & 34 & 3 \\
$\mathrm{TiO}_{2}$-Ti-TM & 20 & 43 & & \\
\hline
\end{tabular}




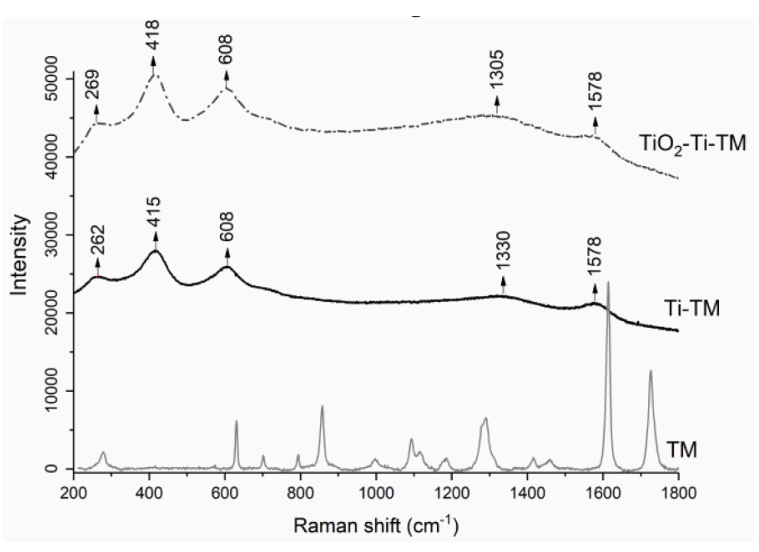

Fig. 5. Raman spectrum of TM, Ti-TM, and $\mathrm{TiO}_{2}-\mathrm{Ti}-\mathrm{TM}$.

$\mathrm{cm}^{-1}$ (transverse acoustic mode), 415/418 $\mathrm{cm}^{-1}$ (transverse optic mode) and $608 \mathrm{~cm}^{-1}$ (longitudinal optic mode) are characteristics of the rutile phase [51-53]. These Raman modes are somewhat shifted in comparison to the literature. However, this could be attributed to laser heating during the analysis or deviations from stoichiometry of the $\mathrm{TiO}_{2}$ films composition which are known to affect both the Raman line positions and widths [52,54]. Furthermore, in the nanocrystalline rutile, non-stoichiometry strongly affects lattice vibrational characteristics, thereby inducing a shape change of oxide Raman lines [55].

Due to the complex nature of the $\mathrm{Ti}^{-\mathrm{TiO}_{2}}$ thin films deposited on top of polyethylene terephthalate track membrane supports, it is difficult to precisely define the nature of these thin films with only one type of analysis. Similarly, it is not uncommon to have contradictory results from different analytical methods such as XPS, EDS and Raman, not only because of the difference in surface sampling depth of these methods, but also the delicate material investigation involved therein. XPS, though not ideal, was found to be the best for investigating the $\mathrm{Ti}$ and $\mathrm{TiO}_{2}$ films.

\subsection{Physical study of contact angle and band gap}

It is difficult to characterise the wettability of a porous film surface, however for the purpose of the study the contact angle of wetting was determined by the method of a recumbent drop. For this technique, the angle between the tangent to the water film and the test surface is measured and based on the results we can comment about the surface hydrophobicity or hydrophilicity. From the results the subsequent change in the hydrophilicity of the track membrane surface post sputtering was discerned. Both $\mathrm{Ti}$ and $\mathrm{TiO}_{2}$-Ti metallisation of the TM surface significantly reduced the contact angle with water from $72^{\circ}$ for untreated PET to $43^{\circ}$ and $45^{\circ}$ for $\mathrm{Ti}-\mathrm{TM}$ and $\mathrm{TiO}_{2}$-Ti-TM respectively, which thus improved hydrophilicity and thus would reduce surface fouling by organic substances [35]. When dealing with photocatalytic thin films on top of TMs, band-gap measurements are of great value as they are fast, non-destructive, give valuable information about the film properties and allow for the confirmation of results when using multiple analytical techniques.

In our previous publication [10] the transmittance was measured as functions of the wavelength of the incident light to study the optical properties of $\mathrm{TiO}_{2}$ thin films, see Fig. 6. During this study various transparent films including $\mathrm{TiO}_{2}$ was investigated, however Ti and $\mathrm{Ti}-\mathrm{TiO}_{2}$ were not. Only $\mathrm{TiO}_{2}$ was investigated because the $\mathrm{Ti}$ and $\mathrm{Ti}-\mathrm{TiO}_{2}$ coatings are not transparent. Using the Tauc plot method, the experimentally measured transmission spectra of the modified TMs were replotted as either direct $(\alpha \mathrm{h} \nu)^{2}$ or indirect $(\alpha \mathrm{h} \nu)^{0.5}$ allowed transitions vs. photon energy $(\mathrm{h} \nu)$. Where $\alpha$ is the absorption coefficient, $h$ is Plank's constant and $v$ the frequency of light. Extrapolating the linear region of these curves to the intersection with the abscissa gives the value of the
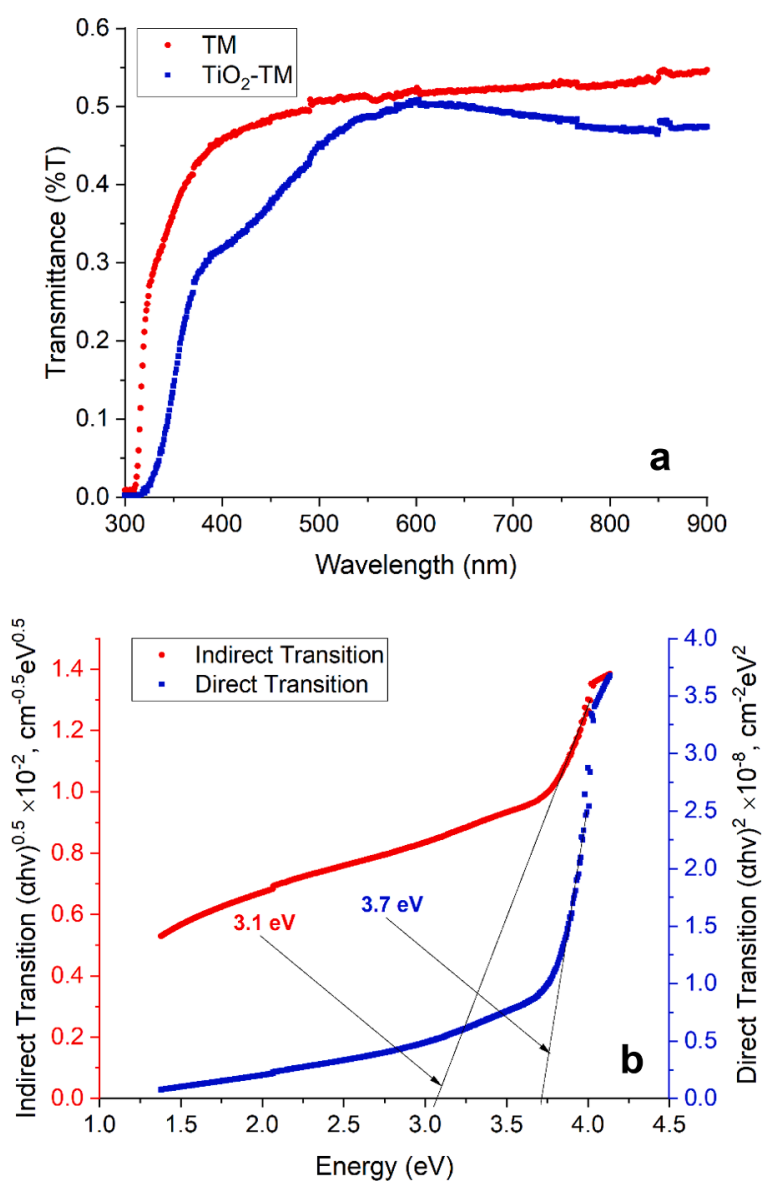

Fig. 6. (a) Optical transmission spectra; (b) Band gap evaluation for indirectand direct transition band gap of $\mathrm{TiO}_{2}$.

indirectly and directly allowed transition band gaps, respectively.

From Raman we have identified rutile peaks, however, after calculating and comparing the energies of indirectly $(3.1 \mathrm{eV})$ and directly $(3.7 \mathrm{eV})$ allowed optical transitions inferred from measured transmission spectra of the $\mathrm{TiO}_{2}$-TM films, see Fig. 6, the presence of anatase phase cannot be ruled out. These results are discussed in detail in our previous article [10].

It should be noted that the calculated band gaps of the titanium dioxide on membranes differ significantly from the literature. However, this may be due to the effect of the surface morphology of the TMs on the structure of the sputter-deposited films. It also follows from the data presented that metallisation of the membranes leads to an increase in band gap. This circumstance can influence the photocatalytic activity and hydrophilic properties of the surface of the thin films [22]. Rutile $\mathrm{TiO}_{2}$ tends to exhibit lower photocatalytic activity than anatase $\mathrm{TiO}_{2}$. Nevertheless, the reason for this difference in photocatalytic activity is still being debated. While both rutile and brookite fall under the direct band gap semiconductor category, anatase seems to be an indirect band gap semiconductor $[24,56]$. This means that should these coated TMs be exposed to a UV light source they would exhibit photocatalytic effects that could aid to extending their lifetime through photocatalytic degradation of dissolved organic matter collecting on top of the membrane surface.

\section{Conclusions}

In this study, the "lab-scale" deposition of $\mathrm{Ti}$ and $\mathrm{Ti}^{-\mathrm{TiO}_{2}}$ thin films by planar magnetron sputtering on top of track etched membrane supports were investigated. AFM and SEM analysis of the modified TM morphology revealed that the $\mathrm{Ti}$ and $\mathrm{Ti}-\mathrm{TiO}_{2}$ thin films seem to be 
composed of fused nanoparticles. Sputter deposition resulted in an increased Rq from $4.6 \pm 0.4 \mathrm{~nm}$ for the initial TM to $5.3 \pm 0.4 \mathrm{~nm}$ for the Ti-TM and $6.4 \pm 0.4 \mathrm{~nm}$ for the $\mathrm{TiO}_{2}$-Ti-TM. It was found that the pore diameter of the native TM was reduced from 0.2 to $0.15 \mu \mathrm{m}$ because of the Ti deposition and a further reduction occurred after the sequential $\mathrm{TiO}_{2}$ deposition reducing the pore diameter to $0.08 \mu \mathrm{m}$. The Ti and $\mathrm{TiO}_{2}$ surface coatings significantly reduced the contact angle from $72^{\circ}$ for $\mathrm{TM}$, to 43 and $45^{\circ}$ for $\mathrm{Ti}$ and $\mathrm{Ti}^{-\mathrm{TiO}_{2}}$, respectively. This increased hydrophilicity of the surface is expected to improve surface interactions in filtration processes, thus reducing surface fouling by organic substances.

Raman confirmed the presence of rutile phase $\mathrm{TiO}_{2}$ and the calculated indirect-, and direct transition band gap of the isolated $\mathrm{TiO}_{2}$ thin film on top of a TM support was estimated at $3.1-3.7 \mathrm{eV}$, however, since the lowest value is generally deemed to be the band gap, the band gap is $3.1 \mathrm{eV}$ and of indirect type.

Both XPS and EDS confirmed the presence of nitrogen in the sputtered thin films, albeit in a low percentage range. The main form of nitrogen is in TiN, most likely arising from the degassing of the TM support and the reaction between Ti clusters and the residual atmosphere during the extended low-vacuum sputtering process. The presence of $\mathrm{TiC}$ is primarily attributed to the TM support with the TiC being a by-product of the surface-sputter interaction between TM and Ti during the initial Ti deposition.

This study clearly shows that planar magnetron sputtering is a viable approach to surface modification of a porous polymeric support such as track etched membranes and can feasibly be scaled up. However, further investigation into the intricacies of metallisation of TMs are recommended. It is believed that the overall quality of the surface coating could be improved upon, resulting in more defined and controlled alterations to the pore surface-properties and an increase to the hydrophilicity of the sputtered film. Taking these improvements into consideration, it is believed that TM surface modification by magnetron sputtering would invigorate the TM market, and also aid the industrial need for finer filtration.

\section{Funding}

This work was funded by the National Research Foundation and the Department of Science and Innovation of South Africa in association with the Joint Institute for Nuclear Research, Russia. A.O. (XPS and AFM) gratefully acknowledge the financial support by the Plenipotentiary Representative of the Republic of Poland at JINR within the project № $75 / 44 / 2020$ and grant № $80 / 12 / 2020$.

\section{CRediT authorship contribution statement}

Arnoux Rossouw: Conceptualization, Investigation, Formal analysis, Writing - original draft, Writing - review \& editing. Olga Kristavchuk: Investigation. Andrzej Olejniczak: Investigation, Formal analysis, Writing - review \& editing. Chris Bode-Aluko: Investigation. Boris Gorberg: Investigation, Validation. Alexander Nechaev: Supervision, Resources. Leslie Petrik: Supervision, Writing - review \& editing. Willem Perold: Supervision, Writing - review \& editing. Pavel Apel: Supervision, Resources.

\section{Declaration of Competing Interest}

"The authors declare no conflict of interest." "The funders had no role in the design of the study; in the collection, analyses, or interpretation of data; in the writing of the manuscript, or in the decision to publish the results".

\section{References}

[1] P. Apel, Track etching technique in membrane technology, Radiat. Meas. 34 (2001) 559-566, https://doi.org/10.1016/S1350-4487(01)00228-1.
[2] P.Y. Apel, Track-Etching, in: Encycl. Membr. Sci. Technol, John Wiley \& Sons, Inc., Hoboken, NJ, USA, 2013, pp. 1-25, https://doi.org/10.1002/9781118522318. emst040.

[3] Z.-.B. He, S.-.L. Guo, Applications of Nuclear Track Membranes to Filtration of Medical Injections and Various Transfusions to Remove Solid Particles, Phys. Procedia. 80 (2015) 131-134, https://doi.org/10.1016/J.PHPRO.2015.11.081.

[4] T.V. Ryazantseva, L.I. Kravets, V.M. Elinson, Use of polymer track membranes with nanostructured surface as drainage in antiglaucomatous operations, Surf. Coatings Technol. 205 (2011) S562-S566, https://doi.org/10.1016/J. SURFCOAT.2011.03.083.

[5] H. Bessbousse, N. Zran, J. Fauléau, B. Godin, V. Lemée, T. Wade, M.-.C. Clochard, Poly(4-vinyl pyridine) radiografted PVDF track etched membranes as sensors for monitoring trace mercury in water, Radiat. Phys. Chem. 118 (2016) 48-54, https://doi.org/10.1016/J.RADPHYSCHEM.2015.03.011.

[6] H.-.Y. Yu, X.-.C. He, L.-.Q. Liu, J.-.S. Gu, X.-.W. Wei, Surface Modification of Poly (propylene) Microporous Membrane to Improve Its Antifouling Characteristics in an SMBR: O2 Plasma Treatment, Plasma Process. Polym. 5 (2008) 84-91, https:// doi.org/10.1002/ppap.200700051.

[7] A. Rossouw, MScEng thesis, Stellenbosch University, 2013.

[8] O.V. Artoshina, A. Rossouw, V.K. Semina, A.N. Nechaev, P.Y. Apel, Structural and physicochemical properties of titanium dioxide thin films obtained by reactive magnetron sputtering, on the surface of track-etched membranes, Pet. Chem. 55 (2015) 759-768, https://doi.org/10.1134/S0965544115100011.

[9] A. Rossouw, O.V. Artoshina, A.N. Nechaev, P.Y. Apel, L. Petrik, W.J. Perold, C. A. Pineda-Vargas, Stable Ion Beam Analysis (RBS and PIXE) Study of Photocatalytic Track-Etched Membranes, Exot. Nucl., World Sci. (2015) 591-596, https://doi. org/10.1142/9789814632041 0065.

[10] O.V. Artoshina, F.O. Milovich, A. Rossouw, B.L. Gorberg, L.D. Iskhakova, R. P. Ermakov, V.K. Semina, Y.K. Kochnev, A.N. Nechaev, P.Y. Apel, Structure and phase composition of thin TiO2 films grown on the surface of metallized tracketched polyethylene terephthalate membranes by reactive magnetron sputtering, Inorg. Mater. 52 (2016) 945-954, https://doi.org/10.1134/S0020168516080021.

[11] P.Y. Apel, I.V. Blonskaya, O.L. Orelovitch, S.N. Dmitriev, Diode-like ion-track asymmetric nanopores: some alternative methods of fabrication, Nucl. Inst. Methods Phys. Res. Sect. B Beam Interact. Mater. Atoms 267 (2009) 1023-1027, https://doi.org/10.1016/J.NIMB.2009.02.012.

[12] L.I. Kravets, S.N. Dmitriev, V.V. Sleptsov, V.M. Elinson, Production of asymmetric track membranes by gas-discharge method, Surf, Coatings Technol. 174-175 (2003) 821-825, https://doi.org/10.1016/S0257-8972(03)00627-3.

[13] P.Y. Apel, V.V. Bashevoy, I.V. Blonskaya, N.E. Lizunov, O.L. Orelovitch, C. Trautmann, Shedding light on the mechanism of asymmetric track etching: an interplay between latent track structure, etchant diffusion and osmotic flow, Phys. Chem. Chem. Phys. 18 (2016) 25421-25433, https://doi.org/10.1039/ C6CP05465J.

[14] U. Diebold, The surface science of titanium dioxide, Surf. Sci. Rep. 48 (2003) 53-229, https://doi.org/10.1016/S0167-5729(02)00100-0.

[15] A.A. Galuska, J.C. Uht, N. Marquez, Reactive and nonreactive ion mixing of Ti films on carbon substrates, J. Vac. Sci. Technol. A Vacuum, Surfaces, Film. 6 (1988) 110-122, https://doi.org/10.1116/1.574992.

[16] T... Wang, S... Zheng, W... Hao, C. Wang, Studies on photocatalytic activity and transmittance spectra of $\mathrm{TiO} 2$ thin films prepared by r.f. magnetron sputtering method, Surf. Coatings Technol. 155 (2002) 141-145, https://doi.org/10.1016/ S0257-8972(02)00004-X.

[17] S.C. Park, S.S. Yoon, J.D. Nam, Surface characteristics and adhesive strengths of metal on O2 ion beam treated polyimide substrate, Thin Solid Films 516 (2008) 3028-3035, https://doi.org/10.1016/J.TSF.2007.11.113.

[18] D. Formation, S. Evolution, Stress, Defect Formation and Surface Evolution, Evolution (N. Y). (2003) 1-820, https://doi.org/10.1017/CBO9780511754715.

[19] Y.G. Shen, Y.W. Mai, Q.C. Zhang, D.R. McKenzie, W.D. McFall, W.E. McBride, Residual stress, microstructure, and structure of tungsten thin films deposited by magnetron sputtering, J. Appl. Phys. 87 (1999), https://doi.org/10.1063/ $1.371841,177$

[20] T. Prasanna Kumari, M. Manivel Raja, A. Kumar, S. Srinath, S.V. Kamat, Effect of thickness on structure, microstructure, residual stress and soft magnetic properties of DC sputtered Fe65Co35 soft magnetic thin films, J. Magn. Magn. Mater. 365 (2014) 93-99, https://doi.org/10.1016/J.JMMM.2014.04.030.

[21] O. CARP, Photoinduced reactivity of titanium dioxide, Prog. Solid State Chem. 32 (2004) 33-177, https://doi.org/10.1016/j.progsolidstchem.2004.08.001.

[22] A. Fujishima, T.N. Rao, D.A. Tryk, Titanium dioxide photocatalysis, J. Photochem. Photobiol. C Photochem. Rev. 1 (2000) 1-21, https://doi.org/10.1016/S13895567(00)00002-2.

[23] X. Chen, S.S. Mao, Titanium dioxide nanomaterials: synthesis, properties, modifications and applications, Chem. Rev. 107 (2007) 2891-2959, https://doi. org/10.1021/cr0500535.

[24] J. Zhang, P. Zhou, J. Liu, J. Yu, New understanding of the difference of photocatalytic activity among anatase, rutile and brookite TiO2, Phys. Chem. Chem. Phys. 16 (2014) 20382-20386, https://doi.org/10.1039/c4cp02201g.

[25] Y.M. Sung, H.J. Kim, Sputter deposition and surface treatment of TiO2films for dye-sensitized solar cells using reactive RF plasma, Thin Solid Films 515 (2007) 4996-4999, https://doi.org/10.1016/j.tsf.2006.10.079.

[26] A.L. Linsebigler, G. Lu, J.T. Yates, Photocatalysis on TiO2 Surfaces: principles, Mechanisms, and Selected Results, Chem. Rev. 95 (1995) 735-758, https://doi. org/10.1021/cr00035a013.

[27] P.Y. Apel, I.V. Blonskaya, S.N. Dmitriev, T.I. Mamonova, O.L. Orelovitch, B. Sartowska, Y. Yamauchi, Surfactant-controlled etching of ion track nanopores 
and its practical applications in membrane technology, Radiat. Meas. 43 (2008) S552-S559, https://doi.org/10.1016/J.RADMEAS.2008.04.057.

[28] T.E. Gómez Álvarez-Arenas, P.Y. Apel, O.L. Orelovitch, M. Muñoz, New ultrasonic technique for the study of the pore shape of track-etched pores in polymer films, Radiat. Meas. 44 (2009) 1114-1118, https://doi.org/10.1016/J. RADMEAS.2009.09.002.

[29] C.C. Harrell, Z.S. Siwy, C.R. Martin, Conical Nanopore Membranes: controlling the Nanopore Shape, Small. 2 (2006) 194-198, https://doi.org/10.1002/ smll.200500196.

[30] H. Zhang, A.U. Mane, X. Yang, Z. Xia, E.F. Barry, J. Luo, Y. Wan, J.W. Elam, S. B. Darling, Visible-Light-Activated Photocatalytic Films toward Self-Cleaning Membranes, Adv. Funct. Mater. 30 (2020), 2002847, https://doi.org/10.1002/ adfm. 202002847.

[31] Y. Lv, C. Zhang, A. He, S.J. Yang, G.P. Wu, S.B. Darling, Z.K. Xu, Photocatalytic Nanofiltration Membranes with Self-Cleaning Property for Wastewater Treatment, Adv. Funct. Mater. (2017) 27, https://doi.org/10.1002/adfm.201700251.

[32] J. Gao, W. Li, X. Zhao, L. Wang, N. Pan, Durable visible light self-cleaning surfaces imparted by $\mathrm{TiO}_{2} / \mathrm{SiO}_{2} / \mathrm{GO}$ photocatalyst, Text. Res. J. 89 (2019) 517-527, https://doi.org/10.1177/0040517517750647.

[33] G.N. Flerov, P.Y. Apel, A.Y. Didyk, V.I. Kuznetsov, R.T. Oganesyan, Use of heavyion accelerators to produce nuclear membranes, Sov. At. Energy. 67 (1989) 763-770, https://doi.org/10.1007/BF01123341.

[34] P.Y. Apel, S.N. Dmitriev, Micro- and nanoporous materials produced using accelerated heavy ion beams, Adv. Nat. Sci. Nanosci. Nanotechnol. 2 (2011), https://doi.org/10.1088/2043-6262/2/1/013002.

[35] L. Kravets, A. Gilman, M. Yablokov, V. Elinson, B. Mitu, G. Dinescu, Surface and electrochemical properties of plasma-treated polypropylene track membrane, Plasma Process. Polym. 10 (2013) 603-618, https://doi.org/10.1002/ ppap. 201200084.

[36] N. Khlebnikov, E. Polyakov, S. Borisov, N. Barashev, E. Biramov, A. Maltceva, A. Vereshchagin, S. Khartov, A. Voronin, Composite materials obtained by the ion-plasma sputtering of metal compound coatings on polymer films, Jpn. J. Appl. Phys. 55 (2016) 01AG02, https://doi.org/10.7567/JJAP.55.01AG02.

[37] C.A. Bode-Aluko, K. Laatikainen, O. Pereao, A. Nechaev, I. Kochnev, A. Rossouw, S. Dobretsov, C. Branger, A. Sarbu, L. Petrik, Fabrication and characterisation of novel nanofiltration polymeric membrane, Mater. Today Commun. 20 (2019), 100580, https://doi.org/10.1016/j.mtcomm.2019.100580.

[38] A.B. Solovieva, V.A. Timofeeva, N.A. Erina, G.V. Vstovsky, A.V. Krivandin, O. V. Shatalova, P.Y. Apel, B.V. McHedlishvili, S.F. Timashev, Peculiarities of the formation of track-etched membranes by the data of atomic force microscopy and X-ray scattering, Colloid J 67 (2005) 217-226, https://doi.org/10.1007/s10595005-0084-6.

[39] M.C. Biesinger, L.W.M. Lau, A.R. Gerson, R.S.C. Smart, Resolving surface chemical states in XPS analysis of first row transition metals, oxides and hydroxides: $s c, \mathrm{Ti}, \mathrm{V}$, Cu and Zn, Appl. Surf. Sci. 257 (2010) 887-898, https://doi.org/10.1016/j. apsusc.2010.07.086.

[40] J.E. Krzanowski, R.E. Leuchtner, Chemical, Mechanical, and Tribological Properties of Pulsed-Laser-Deposited Titanium Carbide and Vanadium Carbide, J. Am. Ceram. Soc. 80 (2005) 1277-1280, https://doi.org/10.1111/j.11512916.1997.tb02976.x.

[41] D. Jaeger, J. Patscheider, A complete and self-consistent evaluation of XPS spectra of TiN, J. Electron Spectros. Relat. Phenomena. 185 (2012) 523-534, https://doi. org/10.1016/j.elspec.2012.10.011.
[42] S. Hashimoto, A. Tanaka, Alteration of Ti 2p XPS spectrum for titanium oxide by low-energy Ar ion bombardment, Surf. Interface Anal. 34 (2002) 262-265, https:// doi.org/10.1002/sia.1296.

[43] A.M. Ektessabi, K. Yamaguchi, Changes in chemical states of PET films due to low and high energy oxygen ion beam, Thin Solid Films. 377-378 (2000) 793-797, https://doi.org/10.1016/S0040-6090(00)01454-1.

[44] S. Pylypenko, K. Artyushkova, J.E. Fulghum, Application of XPS spectral subtraction and multivariate analysis for the characterization of $\mathrm{Ar}+$ ion beam modified polyimide surfaces, Appl. Surf. Sci. 256 (2010) 3204-3210, https://doi. org/10.1016/j.apsusc.2009.12.006.

[45] J.B. Malherbe, S. Hofmann, J.M. Sanz, Preferential sputtering of oxides: a comparison of model predictions with experimental data, Appl. Surf. Sci. 27 (1986) 355-365, https://doi.org/10.1016/0169-4332(86)90139-X.

[46] R. Kelly, On the problem of whether mass or chemical bonding is more important to bombardment-induced compositional changes in alloys and oxides, Surf. Sci. 100 (1980) 85-107, https://doi.org/10.1016/0039-6028(80)90446-X.

[47] M. Kulik, D. Kołodyńska, J. Zuk, A. Bayramov, A. Olejniczak, A. Drozdziel, Dielectric functions E1 and E1 $+\Delta$ in near region of critical points and chemical composition of near surface layers of ions implanted GaAs, Surf. Coatings Technol. 355 (2018) 200-206, https://doi.org/10.1016/j.surfcoat.2018.03.003.

[48] F.Y. Xie, L. Gong, X. Liu, Y.T. Tao, W.H. Zhang, S.H. Chen, H. Meng, J. Chen, XPS studies on surface reduction of tungsten oxide nanowire film by $\mathrm{Ar}+$ bombardment, J. Electron Spectros. Relat. Phenomena. 185 (2012) 112-118, https://doi.org/10.1016/j.elspec.2012.01.004.

[49] E. Lewin, P.O... Persson, M. Lattemann, M. Stüber, M. Gorgoi, A. Sandell, C. Ziebert, F. Schäfers, W. Braun, J. Halbritter, S. Ulrich, W. Eberhardt, L. Hultman, H. Siegbahn, S. Svensson, U. Jansson, On the origin of a third spectral component of C1s XPS-spectra for nc-TiC/a-C nanocomposite thin films, Surf. Coatings Technol. 202 (2008) 3563-3570, https://doi.org/10.1016/j.surfcoat.2007.12.038.

[50] H.C. Choi, Y.M. Jung, S. Bin Kim, Size effects in the Raman spectra of TiO2 nanoparticles, Vib. Spectrosc. (2005), https://doi.org/10.1016/j. vibspec.2004.05.006.

[51] Y. Zhang, C.X. Harris, P. Wallenmeyer, J. Murowchick, X. Chen, Asymmetric lattice vibrational characteristics of rutile TiO 2 as revealed by laser power dependent raman spectroscopy, J. Phys. Chem. C. 117 (2013) 24015-24022, https://doi.org/ 10.1021/jp406948e.

[52] A.N. Da Silva, R.C.F. Pinto, P.T.C. Freire, J.A.L. Junior, A.C. Oliveira, J.M. Filho, Temperature and high pressure effects on the structural features of catalytic nanocomposites oxides by Raman spectroscopy, Spectrochim. Acta - Part A Mol. Biomol. Spectrosc. (2015), https://doi.org/10.1016/j.saa.2014.11.081.

[53] X. Wu, Z. Ming-sheng, Z. Yin, X. Ji, Q. Chen, Temperature Characteristics of Raman Spectra in Nanometer Material Titanium Dioxide, Chinese Phys. Lett. 11 (1994) 685-688, https://doi.org/10.1088/0256-307X/11/11/008.

[54] A. Turković, M. Ivanda, Thermally stimulated currents and Raman spectroscopy of $\mathrm{TiO} 2$ intercalation electrode for $\mathrm{Ag} / \mathrm{AgI} / \mathrm{TiO} 2$ thin film cell, Solid State Ionics 50 (1992) 159-165, https://doi.org/10.1016/0167-2738(92)90048-T.

[55] W.F. Zhang, Y.L. He, M.S. Zhang, Z. Yin, Q. Chen, Raman scattering study on anatase TiO2 nanocrystals, J. Phys. D. Appl. Phys. 33 (2000) 912-916, https://doi. org/10.1088/0022-3727/33/8/305.

[56] V.M. Ievlev, S.B. Kushchev, A.N. Latyshev, L.Y. Leonova, O.V. Ovchinnikov, M. S. Smirnov, E.V. Popova, A.V. Kostyuchenko, S.A. Soldatenko, Absorption spectra of TiO2 thin films synthesized by the reactive radio-frequency magnetron sputtering of titanium, Semiconductors 48 (2014) 848-858, https://doi.org/ 10.1134/S1063782614070094. 